JGG 2022;70:105-112

doi: $10.36150 / 2499-6564-N 382$

\title{
Depressive symptoms and cognitive/ functional status in a sample of elderly subjects referring to a memory clinic
}

\author{
Lisa Marabini ${ }^{1}$, Chiara Pazzaglini ${ }^{1}$, Stefania Bonazzi ${ }^{1}$, Patrizia Guasti ${ }^{1}$, \\ Gianluca Guerra², Amedeo Zurlo², Giovanni Zuliani', Gloria Brombo' \\ ${ }^{1}$ Department of Translational Medicine and for Romagna, University of Ferrara, Ferrara, Italy; \\ ${ }^{2}$ Department of Medical Sciences, Geriatric-Orthogeriatric Unit, University of Ferrara, Ferrara, Italy
}

Received: April 24, 2021

Accepted: October 13, 2021

\section{Correspondence \\ Gloria Brombo \\ Department of Translational Medicine and for \\ Romagna, University of Ferrara, via Aldo Moro 8, I-44124 Ferrara, Italy. Tel.: +390532 237017. \\ Fax: +390532 239547 \\ E-mail: g.brombo@gmail.com}

How to cite this article: Marabini $L$, Pazzaglini C, Bonazzi S, et al. Depressive symptoms and cognitive/functional status in a sample of elderly subjects referring to a memory clinic. Journal of Gerontology and Geriatrics 2022;70:105-112. https://doi. org/10.36150/2499-6564-N382

(C) Copyright by Società Italiana

di Gerontologia e Geriatria (SIGG)

\section{(c) (1) $(\Theta$}

This is an open access article distributed in accordance with the CC-BY-NC-ND (Creative Commons Attribution-NonCommercial-NoDerivatives 4.0 International) license. The article can be used by giving appropriate credit and mentioning the license, but only for non-commercial purposes and only in the original version. For further information: https://creativecommons.org/licenses/by-nc-nd/4.0/deed.en
Background \& aims. Depression and dementia are two frequent conditions in the elderly population and are often associated; their relationship is still debated and not well understood. The aim of our study was to examine the prevalence of depressive symptoms and their possible relationship with other demographic, cognitive, and functional characteristics in a sample of elderly subjects.

Methods. We performed a cross-sectional analysis of 1142 patients ( $\geq 65$ years) admitted to a Memory Clinic. We conducted a multidimensional evaluation including cognitive status, assessment of autonomy in Basic and Instrumental Activities of Daily Living (BADLs and IADLs) and Geriatric Depression Scale (GDS). The sample was stratified by GDS-15 score in three groups $(I:<5$, n. 551 , absence of depressive symptoms; II: $\geq 5$ and < 10, n.442, mild-moderate depression; III: $\geq 10$, n. 149 , severe depression).

Results. Subjects with higher GDS score were more often women, had lower levels of education and haemoglobin $(p<0.001)$. Higher GDS scores were associated with higher score in delayed recall of Rey Auditory Verbal Learning Test (RAVLT, $p<0.001$ ) and Babcock test $(p: 0.05)$, and with lower performance in BADLs and IADLs ( $p: 0.012$ and $p<0.001)$. In linear regression model, all the associations were confirmed.

Conclusions. Our data confirm the relationship between depressive symptoms and female gender, low level of education and greater functional impairment; moreover, we found a significant association between higher GDS score and better scores at memory tests with delayed recall. These results underline the importance of evaluating depressive symptoms as a part of multidimensional evaluation of patients with memory complaints.

Key words: depression, dementia, cognitive assessment, cognitive impairment, functional status

\section{INTRODUCTION}

Depression and dementia are two frequent conditions in the elderly population, and their relationship is still debated and not completely understood. Regarding this topic, at least six different hypothesis have been suggested ${ }^{1,2}: 1_{\text {. depression could be a risk factor for dementia; } 2 .}$ 
depression might reduce the threshold for developing dementia; 3. cognitive impairment could be a feature of depressive syndrome; 4 . depression could be a prodrome of dementia; 5 . depression might be a reaction to early dementia symptoms; 6 . they could belong to an "overlap syndrome", as they share common risk factors and physiopathological pathways. Although depressive symptoms have been reported in about $25 \%$ of patients with any type of dementia (prevalence significantly higher than $13 \%$ found in control subjects without cognitive decline) ${ }^{3}$ and in more than $60 \%$ of patients with Mild Cognitive Impairment (MCl) ${ }^{4,5}$, the prevalence of depression in people with impaired cognitive functions might differ considerably because of differences in populations, severity of dementia, and psychometric indexes used for diagnosis. Depression is generally underdiagnosed and undertreated in elderly people, especially those with dementia, and it has been associated with poorer cognition, physical function and quality of life, greater caregiver burden, and higher mortality risk ${ }^{6-10}$. Late-life depression may be diagnosed according to International Classification of Diseases $10^{\text {th }}$ revision (ICD-10), Diagnostic and Statistical Manual of Mental Disorders (DSM)-V criteria or psychometric indexes. A useful, simple and easily reproducible tool is the Geriatric Depression Scale (GDS); also some short versions of GDS proved to be good screening instruments for depression in elderly population, also compared with standard clinical assessment ${ }^{11,12}$. The GDS score also has the advantages of assessing the severity of depressive symptoms and evaluating potential changes over time. In the present study we report the prevalence of depressive symptoms in a large sample of elderly individuals referring to an Italian memory clinic and analyse potential associations between depressive symptoms and demographic, cognitive, and functional variables.

\section{MATERIAL AND METHODS}

\section{STUdY POPULATION}

We enrolled 1142 consecutive elderly individuals $(\geq 65$ years) admitted from 2006 to 2017 to the Memory Clinic of the Department of Internal Medicine and Geriatrics (S. Anna University Hospital of Ferrara, Italy). The sample included:

- 115 patients with normal cognitive functions and without evidence of any functional disability due to cognitive impairment who accessed the Memory Clinic for subjective impairment or on indication of other medical physicians (no cognitive impairment);

- 66 patients with Vascular Dementia (VD) according to the National Institute of Neurological Disorders and Stroke and Association Internationale pour la Recherche et l'Enseignement en Neuroscience criteria ${ }^{13}$;

- 244 patients with Late Onset Alzheimer Disease (LOAD) according to the NIA-AA workgroups criteria ${ }^{14}$;

- 189 patients with "mixed" dementia. In these patients, a definite diagnosis of LOAD or VD was not possible since both the clinical characteristics of LOAD and VD were present. In particular, while brain computed tomography (CT) scan or magnetic resonance imaging (MRI) demonstrated significant cerebrovascular disease, the evolution of the symptoms was slow and progressive;

- 456 individuals with $\mathrm{MCl}^{5}$, defined as the presence of short/long-term memory impairment, or of impairment in other single or multiple cognitive domains, in an individual who did not meet the standardized criteria for dementia and was still independent in the Instrumental Activities of Daily Living ${ }^{15}$ (IADLs). The majority of these individuals were affected by amnestic multidomain $\mathrm{MCl}$;

- 72 patients with other types of dementia (Lewy body dementia, Parkinson dementia, frontotemporal dementia, alcohol related, psychiatrics, etc.)

The study was carried out in accordance with the Declaration of Helsinki (World Medical Association) and the guidelines/indications for Good Clinical Practice of the European Medicines Agency and of the local Ethics Committee (Ferrara, Italy). Each subject (and/or his caregiver, if demented) gave his written informed consent to the study during the first visit.

\section{Characteristics of the study population}

Sociodemographic characteristics of the study population included age and gender; years of education and history of smoking were ascertained from a baseline interview from patients and caregivers. According to protocol of our Memory Clinic, all patients underwent a general and neurological examination, blood analyses and a neuropsychological assessment, as complete as possible in relation to the patient's ability to perform and carry out the task. We conducted a multidimensional evaluation including Mini Mental State Examination (MMSE) ${ }^{16}$, Basic Activities of Daily Living (BADLs) ${ }^{17}$, IADLS ${ }^{15}$, and 15-item GDS ${ }^{12}$. Trained geriatricians evaluated cognitive performance through a battery of tests ${ }^{18,19}$ and made diagnosis of dementia or $\mathrm{MCl}$. To rule out possible causes of secondary cognitive impairment, clinical chemistry analyses (liver and kidney function, serum folate and vitamin B12, thyroid function, blood cell count, metabolic and lipidic profile and high sensitivity C-reactive protein - hs-CRP) were performed. The prevalence of specific medical conditions 
(hypertension, coronary heart disease - CHD, diabetes mellitus, stroke and hypothyroidism) was established using standardized criteria already reported elsewhere ${ }^{18,19}$. All patients underwent a brain CT or MR. Radiologists not informed about the clinical characteristics of the participants evaluated the acquired radiological imaging. We considered the presence of cortical ischemic lesions, single or multiple lacunar infarcts, leukoaraiosis, and signs of atrophy. Subjects affected by severe congestive heart failure, liver or kidney disease, chronic obstructive pulmonary disease, and cancer were excluded. There was no evidence of acute illnesses at the time of clinical observation and blood sampling. No subject was taking nonsteroidal anti-inflammatory drugs, antibiotics, or steroids at the time of recruitment. We had no data about psychoactive therapy, however patients of our study underwent a complete neuropsychological evaluation for the first time in our Memory Clinic and very rarely they were already taking these types of drugs.

\section{BIOCHEMICAL MEASURES}

Venous blood was sampled after a 12-h over-night fast and promptly analysed using automated techniques in S. Anna Hospital laboratory. Biochemical data were collected on plasma levels of hemoglobin $(\mathrm{g} / \mathrm{dL})$, creatinine $(\mathrm{mg} / \mathrm{dL})$, albumin $(\mathrm{g} / \mathrm{dL})$, total cholesterol $(\mathrm{mg} /$ $\mathrm{dL}$ ), high-density lipoprotein cholesterol (HDL-C, mg/ $\mathrm{dL})$, triglycerides $(\mathrm{mg} / \mathrm{dL})$, homocysteine $(\mu \mathrm{mol} / \mathrm{L})$, vitamin B12 $(\mathrm{pg} / \mathrm{mL})$, folate $(\mathrm{ng} / \mathrm{mL})$, and hs-CRP $(\mathrm{mg} /$ dl). Low-density lipoprotein cholesterol (LDL-C, mg/dL) was calculated using the Friedewald formula ${ }^{20}$.

\section{Statistical ANALYSIS}

The study population was divided in three groups according to GDS score (l: $<5$, n. 551 , absence of depressive symptoms; II: $\geq 5$ and $<10$, n. 442 , mild-moderate depression; III: $\geq 10$, n. 149, severe depression). This categorization was based on previous studies on this topic ${ }^{12,21}$. Clinical, cognitive, functional, neuroradiological, and biochemical characteristics of the study population were compared according to GDS groups. Continuous variables with normal distribution were expressed as means and standard deviations (SD) and compared using the t test or ANOVA. Not normally distributed continuous variables were expressed as medians and interquartile ranges (IQR) and compared using the Kruskal-Wallis test. Categorical variables were compared by the $\chi 2$ test. Neuropsychological tests and functional indexes that resulted associated with GDS at univariate analysis were included into linear regression models, using first GDS score groups and then GSD score as continuous variable. Two models were testes; model 1 unadjusted and model 2 adjusted for potential confounders.
All analyses were performed using Stata 11.0 for Windows (Stata Corporation, College Station, TX, USA).

\section{RESULTS}

Mean age of the sample was $78.3 \pm 5.4$ years; females were 730 (63.9\%). The median GDS score was 5 (IQR: $2-7)$, and 591 (51.8\%) patients presented depressive symptoms (GDS $\geq 5)$.

The principal characteristics of the population according to GDS score are reported in Table I. Subjects with higher GDS score were more often women, had a lower level of education, and lower haemoglobin levels; a greater prevalence of hypertension was also noted in patients with mild-moderate depression (GDS score 5-9).

In Table II are described the cognitive, functional, and neuroradiological characteristics of the sample, according to GDS score. No relationship was found between MMSE and GDS score. In contrast, higher GDS scores were associated with higher scores in delayed recall of Rey Auditory Verbal Learning Test (RAVLT), as well as delayed recall in Babcock test. Subjects with more depressive symptoms also displayed a lower functional autonomy in BADL and IADL. In particular, a loss of autonomy in all basic activities (except for feeding), and in all instrumental activities (except for using the phone) was associated with higher GDS score (data not shown). No association was found between GDS score and neuroimaging findings.

In Table III are reported the results of linear regression models for the relationship between GDS score groups and selected neurocognitive and functional tests. All the associations were confirmed, except for delayed recall of RAVLT (associated only with the group GDS 5-9), after adjustment for age, gender, years of education, and MMSE score.

As reported in Table IV, when GDS score was considered as a continuous variable, the associations with delayed recall of RAVLT and of Babcock test and with BADLs and IADLs were demonstrated. As regards the Token test, its association with GDS was not confirmed after adjustment for confounding factors.

We further analysed the relationships between GDS score and cognitive/functional tests stratifying the sample based on diagnosis (no cognitive impairment, $\mathrm{MCl}$ and dementia) (data not shown). Compared with the result described above, no differences emerged in patients without cognitive impairment. Among MCl, GDS score was associated with delayed recall of RAVLT, BADLs and IADLs but not with delayed Babcock test. Among patients with dementia, GDS score was associated with delayed Babcock test and IADLs but not with delayed recall of RAVLT and BADLs. 
Table I. Demographic, biochemical, and clinical characteristics of study population according to Geriatric Depression Scale (GDS) score.

\begin{tabular}{|c|c|c|c|c|}
\hline Characteristics & $\begin{array}{c}\text { GDS }<5 \\
(n=551,48.2 \%)\end{array}$ & $\begin{array}{c}\text { GDS 5-9 } \\
(n=442,38.7 \%)\end{array}$ & $\begin{array}{c}\text { GDS } \geq 10 \\
(n=149,13.1 \%)\end{array}$ & $\boldsymbol{P}$ \\
\hline Age (years), mean $\pm S D$ & $78.3 \pm 5.4$ & $78.5 \pm 5.6$ & $77.8 \pm 4.9$ & 0.430 \\
\hline Female sex, $\mathrm{n}(\%)$ & $311(56.4)$ & $299(67.7)$ & $120(80.5)$ & $<0.001$ \\
\hline Education (years), mean $\pm \mathrm{SD}$ & $6.6 \pm 4.0$ & $6.4 \pm 3.5$ & $5.2 \pm 3.3$ & $<0.001$ \\
\hline Smoking (past or current), $n$ (\%) & $234(42.5)$ & $174(39.4)$ & $66(44.3)$ & 0.581 \\
\hline \multicolumn{5}{|c|}{ Biochemical parameters, mean \pm SD } \\
\hline Hemoglobin (g/dl) & $13.4 \pm 1.5$ & $13.0 \pm 1.5$ & $12.8 \pm 1.5$ & $<0.001$ \\
\hline Creatinine $(\mathrm{mg} / \mathrm{dl})$ & $0.98 \pm 0.36$ & $0.99 \pm 0.43$ & $0.97 \pm 0.52$ & 0.923 \\
\hline Albumin (g/dl) & $4.0 \pm 0.4$ & $4.0 \pm 0.3$ & $4.0 \pm 0.4$ & 0.931 \\
\hline Total cholesterol (mg/dl) & $205.8 \pm 39.8$ & $209.3 \pm 44.0$ & $211.9 \pm 38.7$ & 0.192 \\
\hline Triglycerides (mg/dl) & $110.3 \pm 48.0$ & $117.2 \pm 56.7$ & $117.4 \pm 51.2$ & 0.077 \\
\hline LDL cholesterol (mg/dl) & $122.9 \pm 34.2$ & $126.2 \pm 38.6$ & $127.0 \pm 33.8$ & 0.256 \\
\hline $\mathrm{Hs}-\mathrm{CRP}(\mathrm{mg} / \mathrm{dl})^{\star}$ & $0.16(0.08-0.38)$ & $0.18(0.09-0.38)$ & $0.2(0.1-0.4)$ & 0.609 \\
\hline Homocysteine $(\mu \mathrm{mol} / \mathrm{l})$ & $18.5 \pm 10.5$ & $18.3 \pm 11.1$ & $19.7 \pm 16.4$ & 0.632 \\
\hline Vitamin B12 $(\mathrm{pg} / \mathrm{ml})^{\star}$ & $305(212-421)$ & $316(242-453)$ & $346.5(238-469)$ & 0.06 \\
\hline Folate $(\mathrm{ng} / \mathrm{ml})$ & $6.7 \pm 3.4$ & $7.0 \pm 4.1$ & $6.8 \pm 3.7$ & 0.373 \\
\hline \multicolumn{5}{|l|}{ Medical conditions, n (\%) } \\
\hline Hypertension & $345(62.6)$ & $313(70.8)$ & $93(62.4)$ & 0.02 \\
\hline Coronary heart disease & 73 (13.3) & $64(14.5)$ & $27(18.1)$ & 0.310 \\
\hline Diabetes & $77(14)$ & $79(17.9)$ & $26(17.5)$ & 0.216 \\
\hline Stroke & $17(3.1)$ & $21(4.8)$ & $9(6)$ & 0.353 \\
\hline Hypothyroidism & $67(12.2)$ & $48(10.9)$ & $17(11.4)$ & 0.811 \\
\hline \multicolumn{5}{|l|}{ Cognitive status, n (\%) } \\
\hline No cognitive impairment & $44(8)$ & $53(12)$ & $18(12.1)$ & \\
\hline Vascular dementia & $31(5.6)$ & $24(5.4)$ & $11(7.4)$ & \\
\hline Late onset Alzheimer's disease & $131(23.8)$ & $85(19.2)$ & $28(18.8)$ & \\
\hline "Mixed" dementia & $95(17.2)$ & $68(15.4)$ & $26(17.4)$ & \\
\hline Mild cognitive impairment & $221(40.1)$ & $182(41.2)$ & $53(35.6)$ & \\
\hline Other types of dementia & $29(5.3)$ & $30(6.8)$ & $13(8.7)$ & 0.269 \\
\hline
\end{tabular}

* value expressed as median (IQR)

\section{DISCUSSION}

\section{DEMOGRAPHIC, BIOCHEMICAL, AND FUNCTIONAL CHARACTERISTICS}

We investigated the prevalence of depressive symptoms (measured by GDS) and their possible relationship with demographic, cognitive, and functional characteristics in a large sample of elderly people referring to an Italian memory clinic.

We found that depressive symptoms were more frequent in female sex. This finding confirms previous data from literature, since several studies found that depressive disorders are approximately twice as common in women compared to men ${ }^{22,23}$. Noble suggested the involvement of several biological processes (genetically determined vulnerability, hormonal fluctuations, and a hormonal sensitivity in brain systems) and environmental factors in the predisposition of women to depression ${ }^{24}$.
The association between depressive symptoms and lower formal education might be linked to the "resource substitution theory" 25,26; education would improve well-being more for women than for men. Indeed, previous studies demonstrated that the negative relationship between levels of education and depression is much more stronger in women compared with men.

Depressive symptoms were also associated with lower haemoglobin levels, although within the normal range. Previous studies found that anaemia is associated with depressive symptoms ${ }^{27-31}$; anaemia could be the expression of other diseases (e.g. cancer, renal failure, infectious disease, malnutrition) which in turn can worsen the quality of life and lead to depressive symptoms ${ }^{32}$. A greater functional impairment was found in patients with severe depressive symptoms, and this underlines the importance of evaluating/managing functional status and depressive symptoms in patients with cognitive 
Table II. Cognitive, functional, and neuroradiological characteristics of study population according to Geriatric Depression Scale (GDS) score.

\begin{tabular}{|c|c|c|c|c|}
\hline Characteristics & $\begin{array}{c}\text { GDS }<5 \\
(n=551,48.2 \%)\end{array}$ & $\begin{array}{c}\text { GDS 5-9 } \\
\text { (n = } 442,38.7 \%)\end{array}$ & $\begin{array}{c}\text { GDS } \geq 10 \\
(n=149,13.1 \%)\end{array}$ & $P$ \\
\hline \multicolumn{5}{|c|}{ Neurocognitive tests, mean \pm SD } \\
\hline Mini Mental State Examination (/30) & $22.9 \pm 4.1$ & $23.0 \pm 3.9$ & $22.3 \pm 4.1$ & 0.167 \\
\hline $\begin{array}{l}\text { Rey Auditory Verbal Learning test, } \\
\text { immediate recall (/75) }\end{array}$ & $28.7 \pm 9.9$ & $29.8 \pm 9.5$ & $29.4 \pm 9.4$ & 0.284 \\
\hline $\begin{array}{l}\text { Rey Auditory Verbal Learning test, } \\
\text { delayed recall (/15) }\end{array}$ & $3.8 \pm 3.2$ & $4.5 \pm 2.9$ & $4.6 \pm 3.2$ & $<0.001^{*}$ \\
\hline Raven matrix test (/36) & $22.5 \pm 6.2$ & $22.3 \pm 5.9$ & $22.2 \pm 5.2$ & 0.810 \\
\hline Trail Making test $\mathrm{A}$ (sec) & $123.9 \pm 78.4$ & $142 \pm 89.7$ & $134.7 \pm 71.2$ & $0.144^{\star}$ \\
\hline Trail Making test B (sec) & $235.3 \pm 133.4$ & $218.5 \pm 101$ & $233 \pm 117.3$ & $0.826^{*}$ \\
\hline Token test (/36) & $29.1 \pm 4.3$ & $28.5 \pm 4.2$ & $28.1 \pm 4.1$ & 0.172 \\
\hline Verbal fluency test per letter (n) & $12.6 \pm 8.6$ & $13.4 \pm 9.8$ & $11.5 \pm 8.2$ & $0.195^{\star}$ \\
\hline Verbal fluency test per category (n) & $18.3 \pm 15$ & $18.4 \pm 14.3$ & $16.0 \pm 12.9$ & $0.269^{\star}$ \\
\hline Babcock test, immediate recall (/8) & $3.3 \pm 2.3$ & $3.6 \pm 2.2$ & $3.4 \pm 2.2$ & 0.167 \\
\hline Babcock test, delayed recall (/8) & $3.2 \pm 2.8$ & $3.6 \pm 2.5$ & $3.7 \pm 2.7$ & 0.05 \\
\hline Frontal assessment battery (/18) & $11.9 \pm 3.5$ & $11.6 \pm 3.6$ & $11.5 \pm 3.8$ & $0.605^{\wedge}$ \\
\hline \multicolumn{5}{|l|}{ Functional tests, mean \pm SD } \\
\hline Barthel index (/100) & $92.0 \pm 16.0$ & $86.6 \pm 22.8$ & $85.1 \pm 22.2$ & $0.015^{\wedge}$ \\
\hline Lawton-Brody scale (/19) & $15.4 \pm 3.8$ & $14.1 \pm 4.3$ & $13.2 \pm 4.2$ & $<0.001^{\wedge}$ \\
\hline \multicolumn{5}{|c|}{ Radiological characteristics, n (\%) } \\
\hline Cortical ischemic lesions & $52(9.4)$ & $52(11.8)$ & $16(10.7)$ & 0.481 \\
\hline Single lacunar lesion & $40(7.3)$ & $34(7.7)$ & $5(3.4)$ & 0.143 \\
\hline Multiple lacunar lesions & $165(30)$ & $126(28.5)$ & $40(26.9)$ & 0.576 \\
\hline Leukoaraiosis & $223(40.5)$ & $185(41.9)$ & $65(43.6)$ & 0.88 \\
\hline Atrophy & $310(56.3)$ & $243(55)$ & $86(57.7)$ & 0.945 \\
\hline
\end{tabular}

*significance calculated with normalized variables with their square root. $\wedge$ significance calculated with normalized variables with their exponential value.

Table III. Linear regression models (not adjusted and adjusted for potential confounders) for the relationship between Geriatric Depression Scale (GDS) score groups and selected cognitive and functional tests.

\begin{tabular}{|c|c|c|c|c|c|c|c|c|}
\hline & \multicolumn{2}{|c|}{$\begin{array}{l}\text { RAVLT, delayed recall } \\
(P)\end{array}$} & \multicolumn{2}{|c|}{$\begin{array}{l}\text { Babcock test, } \\
\text { delayed recall }(P)\end{array}$} & \multicolumn{2}{|c|}{$\begin{array}{l}\text { Barthel } \\
\text { index }(P)\end{array}$} & \multicolumn{2}{|c|}{$\begin{array}{l}\text { Lawton-Brody scale } \\
\text { (P) }\end{array}$} \\
\hline & $\begin{array}{c}\text { Coeff } \\
\text { (M1) }\end{array}$ & $\begin{array}{l}\text { Coeff } \\
\text { (M2) }\end{array}$ & $\begin{array}{c}\text { Coeff } \\
\text { (M1) }\end{array}$ & $\begin{array}{c}\text { Coeff } \\
\text { (M2) }\end{array}$ & $\begin{array}{l}\text { Coeff } \\
\text { (M1) }\end{array}$ & $\begin{array}{l}\text { Coeff } \\
(\mathrm{M} 2)^{*}\end{array}$ & $\begin{array}{c}\text { Coeff } \\
\text { (M1) }\end{array}$ & $\begin{array}{l}\text { Coeff } \\
\text { (M2)* }\end{array}$ \\
\hline GDS $<5$ & - & - & - & - & - & - & - & - \\
\hline GDS 5-9 & $\begin{array}{c}0.66 \\
(0.002)\end{array}$ & $\begin{array}{c}0.82 \\
(<0.001)\end{array}$ & $0.37(0.044)$ & $\begin{array}{c}0.50 \\
(0.009)\end{array}$ & $-5.5(0.024)$ & $\begin{array}{l}-4.24 \\
(0.05)\end{array}$ & $-1.30(0.001)$ & $\begin{array}{c}-1.26 \\
(<0.001)\end{array}$ \\
\hline GDS $\geq 10$ & $0.81(0.011)$ & $0.57(0.073)$ & $0.53(0.057)$ & $\begin{array}{c}0.59 \\
(0.035)\end{array}$ & $-6.91(0.026)$ & $\begin{array}{c}-8.09 \\
(0.005)\end{array}$ & $\begin{array}{c}-2.19 \\
(<0.001)\end{array}$ & $\begin{array}{c}-1.76 \\
(<0.001)\end{array}$ \\
\hline
\end{tabular}

Coefficient indicates the variation of the variable in each group compared to the reference group (GDS score $<5$ ). M1: not adjusted model; M2: model adjusted for age, gender and years of education; M2*: model adjusted for age, gender, years of education, and MMSE score.

impairment. The relationship between depressive symptoms and functional performance has been already reported in previous studies ${ }^{33-37}$. Functional dependence is a risk factor for depression and vice versa ${ }^{38}$; moreover, among depressed people, dependence in IADLs has been associated with a greater cognitive impairment ${ }^{39}$, and with the persistence of cognitive impairment after depression remission ${ }^{40}$.

\section{Neurocognitive Characteristics}

By analysing the association between depressive symptoms and cognitive performance, we expanded the results of previous studies. We found an interesting relationship between depressive symptoms and higher score in delayed memory recall of RAVLT and Babcock tests. In case of a pure depressive disorder, there is 
Table IV. Linear regression models (not adjusted and adjusted for potential confounders) between Geriatric Depression Scale (GDS) score, as continuous variable, and selected neurocognitive and functional tests.

\begin{tabular}{|l|c|c|}
\hline $\begin{array}{l}\text { Rey Auditory Verbal Learning } \\
\text { test, delayed recall }\end{array}$ & Coeff $(\boldsymbol{P})$ & Coeff $(\boldsymbol{P})$ \\
\hline Token test & $0.10(\mathbf{0 . 0 0 4})$ & $0.11(\mathbf{0 . 0 0 8})^{\star}$ \\
\hline Babcock test, delayed recall & $-0.097(\mathbf{0 . 0 1 4})$ & $-0.056(0.196)^{\star}$ \\
\hline Barthel index & $0.10(\mathbf{0 . 0 1 7})$ & $0.13(\mathbf{0 . 0 0 4})^{\star}$ \\
\hline Lawton-Brody scale & $-0.025(\mathbf{0 . 0 1 1})$ & $-0.033(\mathbf{0 . 0 0 3}) \#$ \\
\hline
\end{tabular}

*adjusted for age, gender and years of education; \# adjusted for age, gender, years of education, and MMSE score

no memory storage deficit, at the expense of attention difficulties. Memory may appear compromised, but depressed people can often find the correct solution with additional thinking time or mnemonic cues. In AD, instead, the ability to store new information is damaged and information can be difficultly retrieved ${ }^{41}$.

Previous studies demonstrated as a normal recall is typically found in major depression, whereas a flat learning curve and a rapid forgetting are typical for AD ${ }^{42-44}$. Indeed, as demonstrated by Dannenbaum et al. ${ }^{45}$, subjects with depression perform better than $A D$ patients in all initial learning and recall, as well as in delayed recall measures. Niederehe et al. ${ }^{46}$ found that depressed and mildly demented patients displayed similar performance in psychomotor speed, but the recall of symbols was significantly better in depressed than in mild $A D$. From the neurobiological point of view, these deficits could be explained by a general cognitive inefficiency and attention problem in depressed patients, rather than a to structural deficits.

Despite some strengths (high sample size, detailed neuropsychological characterization of participants, adjustment for potential confounders), important limitations of our study should be acknowledged. First, the analyses are based on cross-sectional data, limiting any causal interpretation of our results. Second, we do not have detailed information about possible antidepressant drug treatments or information on the onset and duration of depressive symptoms. Third, the categorization of people according to depressive symptoms is based on the GDS scale and not on ICD-10 or DSM-V clinical criteria.

In conclusion, in a large sample of elderly people referring to an Italian memory clinic, individuals with depressive symptoms were more often women, had a lower level of education, presented a greater functional impairment, and better scores at memory tests with delayed recall. These results underline the importance of evaluating depressive symptoms as part of a complete multidimensional evaluation of patients with memory loss in order to improve diagnosis, safeguard functional autonomy and possibly start a target therapy.
Ethical consideration

The study was carried out in accordance with the Declaration of Helsinki (World Medical Association) and the guidelines/indications for Good Clinical Practice of the European Medicines Agency and of the local Ethics Committee (Ferrara, Italy).

Acknowledgement

Everyone who contributed significantly to the work appears in the list of authors.

Conflict of interest

The Authors declare no conflict of interest.

\section{Funding}

This research did not receive any specific grant from funding agencies in the public, commercial, or not-forprofit sectors.

\section{References}

1 Bennett S, Thomas AJ. Depression and dementia: cause, consequence or coincidence? Maturitas 2014;79:184190. https://doi.org/10.1016/j.maturitas.2014.05.009

2 Soavi C, Zuliani G. Depressione nella demenza: fattore di rischio, predittore o sintomo prodromico? Psicogeriatria 2017;2:38-47

3 Kuring JK, Mathias JL, Ward L. Prevalence of depression, anxiety and PTSD in people with dementia: a systematic review and meta-analysis. Neuropsychol Rev 2018;28:393416. https://doi.org/10.1007/s11065-018-9396-2

4 Panza F, Frisardi V, Capurso C, et al. Late-life depression, mild cognitive impairment, and dementia: possible continuum? Am J Geriatr Psychiatry 2010;18:98-116. https:// doi.org/10.1097/JGP.0b013e3181b0fa13

5 Petersen RC. Mild cognitive impairment as a diagnostic entity. J Intern Med 2004;256:183-194. https://doi. org/10.1111/j.1365-2796.2004.01388.x

6 Brown EL, Raue P, Halpert KD, et al. Detection of depression in older adults with dementia. J Gerontol Nurs 2009;35:11 15. https://doi.org/10.3928/00989134-20090201-08 
7 Watson LC, Garrett JM, Sloane PD, et al. Depression in assisted living: results from a four-state study. Am J Geriatr Psychiatry 2003;11:534-542. https://doi. org/10.1097/00019442-200309000-00008

8 Snowden MB, Atkins DC, Steinman LE, et al. Longitudinal association of dementia and depression. Am J Geriatr Psychiatry 2015;23:897-905. https://doi.org/10.1016/j. jagp.2014.09.002

9 Leontjevas R, Gerritsen DL, Vernooij-Dassen MJ, et al. Comparative validation of proxy-based Montgomery-Åsberg depression rating scale and cornell scale for depression in dementia in nursing home residents with dementia. Am J Geriatr Psychiatry 2012;20:985-993. https://doi. org/10.1097/JGP.0b013e318233152b

10 Modrego PJ, Ferrández J. Depression in patients with mild cognitive impairment increases the risk of developing dementia of Alzheimer type: a prospective cohort study. Arch Neurol 2004;61:1290-1293. https://doi.org/10.1001/ archneur.61.8.1290

11 Sheikh JI, Yesavage JA. Geriatric Depression Scale (GDS): recent evidence and development of a shorter version. Clin Gerontol 1986;5:165-173. https://doi.org/10.1300/ J018v05n01_09

12 Almeida OP, Almeida SA. Short versions of the geriatric depression scale: a study of their validity for the diagnosis of a major depressive episode according to ICD-10 and DSM-IV. Int J Geriatr Psychiatry 1999;14:858-865. https:// doi.org/10.1002/(sici)1099-1166(199910)14:10<858::aidgps35>3.0.co;2-8

13 Román GC, Tatemichi TK, Erkinjuntti T, et al. Vascular dementia: diagnostic criteria for research studies. Report of the NINDS-AIREN International Workshop. Neurology 1993;43:250-260. https://doi.org/10.1212/wnl.43.2.250

14 McKhann GM, Knopman DS, Chertkow H, et al. The diagnosis of dementia due to Alzheimer's disease: recommendations from the National Institute on Aging-Alzheimer's Association workgroups on diagnostic guidelines for Alzheimer's disease. Alzheimers Dement 2011;7:263-269. https://doi.org/10.1016/j.jalz.2011.03.005

15 Lawton MP, Brody EM. Assessment of older people: self-maintaining and instrumental activities of daily living. Gerontologist 1969;9:179-186. https://doi.org/10.1093/ geront/9.3_Part_1.179

16 Folstein MF, Folstein SE, McHugh PR. "Mini-mental state". A practical method for grading the cognitive state of patients for the clinician. J Psychiatr Res 1975;12:189-198. https://doi.org/10.1016/0022-3956(75)90026-6

17 Katz S, Ford AB, Moskowitz RW, et al. Studies of illness in the aged. The index of ADL: a standardized measure of biological and psychosocial function. JAMA 1963;185:914-919. https://doi.org/10.1001/jama.1963.03060120024016

18 Zuliani G, Ranzini M, Guerra G, et al. Plasma cytokines profile in older subjects with late onset Alzheimer's disease or vascular dementia. J Psychiatr Res 2007;41:686-693. https://doi.org/10.1016/j.jpsychires.2006.02.008
19 Tisato V, Rimondi E, Brombo G, et al. Serum soluble tumor necrosis factor-related apoptosis-inducing ligand levels in older subjects with dementia and mild cognitive impairment. Dement Geriatr Cogn Disord 2016;41:273-280. https://doi.org/10.1159/000446275

20 Friedewald WT, Levy RI, Fredrickson DS. Estimation of the concentration of low-density lipoprotein cholesterol in plasma, without use of the preparative ultracentrifuge. Clin Chem 1972;18:499-502.

21 Conradsson M, Rosendahl E, Littbrand H, et al. Usefulness of the Geriatric Depression Scale 15-item version among very old people with and without cognitive impairment. Aging Ment Health 2013;17:638-645. https://doi.org/10. 1080/13607863.2012.758231

22 Murray CJ, Lopez AD. Alternative projections of mortality and disability by cause 1990-2020: Global Burden of Disease Study. Lancet 1997;349:1498-1504. https://doi. org/10.1016/S0140-6736(96)07492-2

23 Albert PR. Why is depression more prevalent in women? J Psychiatry Neurosci 2015;40:219-221. https://doi. org/10.1503/jpn.150205

24 Noble RE. Depression in women. Metabolism 2005;54(5 Suppl 1):49-52. https://doi.org/10.1016/j. metabol.2005.01.014

25 Ross CE, Mirowsky J. Explaining the social patterns of depression: control and problem solving - or support and talking? J Health Soc Behav 1989;30:206-219. https:// doi.org/10.2307/2137014

26 Ross CE, Mirowsky J. Sex differences in the effect of education on depression: resource multiplication or resource substitution? Soc Sci Med 2006;63:1400-1413. https:// doi.org/10.1016/j.socscimed.2006.03.013

27 den Elzen WP, Willems JM, Westendorp RG, et al. Effect of anemia and comorbidity on functional status and mortality in old age: results from the Leiden 85-plus Study. CMAJ 2009;181:151-157. https://doi.org/10.1503/cmaj.090040

28 Hamer M, Molloy GJ. Cross-sectional and longitudinal associations between anemia and depressive symptoms in the English Longitudinal Study of Ageing. J Am Geriatr Soc 2009;57:948-949. https://doi. org/10.1111/j.1532-5415.2009.02250.x

29 Onder G, Penninx BW, Cesari M, et al. Anemia is associated with depression in older adults: results from the $\mathrm{InCHI}-$ ANTI study. J Gerontol A Biol Sci Med Sci 2005;60:11681172. https://doi.org/10.1093/gerona/60.9.1168

30 Steptoe A, Wikman A, Molloy GJ, et al. Anaemia and the development of depressive symptoms following acute coronary syndrome: longitudinal clinical observational study. BMJ Open. 2012;2:e000551. https://doi.org/10.1136/ bmjopen-2011-000551

31 Stewart R, Hirani V. Relationship between depressive symptoms, anemia, and iron status in older residents from a national survey population. Psychosom Med 2012;74:208213. https://doi.org/10.1097/PSY.0b013e3182414f7d

32 Thomas DR. Anemia and quality of life: unrecognized and undertreated. J Gerontol A Biol Sci Med Sci 2004;59:238241. https://doi.org/10.1093/gerona/59.3.m238 
33 Thyrian JR, Eichler T, Reimann M, et al. Depressive symptoms and depression in people screened positive for dementia in primary care - results of the DelpHi-study. Int Psychogeriatr 2016;28:929-937. https://doi.org/10.1017/ S1041610215002458

34 Wada T, Ishine M, Sakagami T, et al. Depression in Japanese community-dwelling elderly -prevalence and association with ADL and QOL. Arch Gerontol Geriatr 2004;39:1523. https://doi.org/10.1016/j.archger.2003.12.003

35 Haupt M, Kurz A, Greifenhagen A. Depression in Alzheimer's disease: phenomenological features and association with severity and progression of cognitive and functional impairment. Int J Geriatr Psychiatry 1995;10:469-476. https://doi.org/10.1002/gps.930100606

36 Pearson JL, Teri L, Reifler BV, et al. Functional status and cognitive impairment in Alzheimer's patients with and without depression. J Am Geriatr Soc 1989;37:1117-1121. https://doi.org/10.1111/j.1532-5415.1989.tb06674.x

37 Fitz AG, Teri L. Depression, cognition, and functional ability in patients with Alzheimer's disease. J Am Geriatr Soc 1994;42:186-191. https://doi. org/10.1111/j.1532-5415.1994.tb04950.x

38 Tinetti ME, Inouye SK, Gill TM, et al. Shared risk factors for falls, incontinence, and functional dependence. Unifying the approach to geriatric syndromes. JAMA 1995;273:1348-1353. https://doi.org/10.1001/ jama.1995.03520410042024

39 Steffens DC, Hays JC, Krishnan KR. Disability in geriatric depression. Am J Geriatr Psychiatry 1999;7:34-40. https:// doi.org/10.1097/00019442-199902000-00005
40 Lee JS, Potter GG, Wagner HR, et al. Persistent mild cognitive impairment in geriatric depression. Int Psychogeriatr 2007;19:125-135. https://doi.org/10.1017/ S1041610206003607

41 Tounsi H, Deweer B, Ergis AM, et al. Sensitivity to semantic cuing: an index of episodic memory dysfunction in early Alzheimer disease. Alzheimer Dis Assoc Disord 1999;13:38-46. https://doi.org/10.1097/00002093-199903000-00006

42 Fossati P, Harvey PO, Le Bastard G, et al. Verbal memory performance of patients with a first depressive episode and patients with unipolar and bipolar recurrent depression. J Psychiatr Res 2004;38:137-144. https://doi. org/10.1016/j.jpsychires.2003.08.002

43 Grober E, Buschke H. Genuine memory deficit in dementia. Dev Neuropsychol 2006;3:13-36. https://doi. org/10.1080/87565648709540361

44 Buschke H, Sliwinski MJ, Kuslansky G, et al. Diagnosis of early dementia by the Double Memory Test: encoding specificity improves diagnostic sensitivity and specificity. Neurology 1997;48:989-997. https://doi.org/10.1212/ wnl.48.4.989

45 Dannenbau SE, Parkinson SR, Inman WW. Short-term forgetting: comparisons between patients with dementia of the Alzheimer type, depressed and normal elderly. Cogn Neuropsychol 1988;5:213-233. https://doi. org/10.1080/02643298808252934

46 Niederehe G. Depression and memory impairment in the aged. In: Poon L, Ed. Handbook for clinical memory assessment of older adults. Washington: American Psychological Association. 198, pp. 226-237. 